\title{
Fault Location Method for STATCOM Connected Transmission Lines Using CCM
}

\author{
R. Ilango ${ }^{*}$, T. Sree Renga Raja ${ }^{2}$ \\ ${ }^{1}$ Department of Electrical and Electronics Engineering, M.A.M. School of Engineering, Tiruchirappalli, \\ India \\ ${ }^{2}$ Department of Electrical and Electronics Engineering, Anna University, BIT Campus, Tiruchirappalli, \\ India \\ Email: ilangorengaraju@gmail.com, renga_raja@rediffmail.com
}

Received 6 May 2016; accepted 18 May 2016; published 22 August 2016

Copyright (C) 2016 by authors and Scientific Research Publishing Inc.

This work is licensed under the Creative Commons Attribution International License (CC BY).

http://creativecommons.org/licenses/by/4.0/

(c) () Open Access

\section{Abstract}

Determining the fault location using conventional impedance based distance relay in the presence of FACTS controllers is a challenging task in a transmission line. A new distance protection method is developed to locate the fault in a transmission line compensated with STATCOM with simple calculations. The proposed protection method considers the STATCOM injected/absorbed current to correct the fault loop apparent impedance and accordingly calculates the actual distance to the fault location. The comprehensive equations needed for apparent impedance calculation are also outlined and the performance is evaluated and tested with a typical $400 \mathrm{KV}$ transmission system for different fault types and locations using MATLAB/SIMULINK software. The evaluation results indicate that the new protection method effectively estimates the exact fault location by mitigating the impact of STATCOM on distance relay performance with error less than $0.3 \%$.

\section{Keywords}

Distance Relay, Fault Location, Flexible AC Transmission Systems (FACTS),

Power System Protection, Static Synchronous Compensator (STATCOM)

\section{Introduction}

The demand of electrical power is tremendously increasing throughout the world, day by day, which causes the existing transmission line to increase power transfer capability. The power transfer capability of a transmission line can be improved by using reactive power compensation. The Flexible Alternating Current Transmission

"Corresponding author. 
Systems (FACTS) incorporating power electronic based static controllers have been playing a vital role for the past two decades in supporting reactive power compensation, thus enhancing controllability and increasing power transfer capability of the existing transmission lines [1] [2]. Static Synchronous Compensator (STATCOM) is one of the most widely used shunt FACTS controller, normally connected at the midpoint of the transmission line to maintain the connecting point voltage nearly stable by injecting or absorbing reactive power into the transmission line system [3] [4].

These STATCOM devices introduces some rapid changes in the line parameters like, line currents, line voltages at the relay point in both steady and transient state conditions, which intern changes the apparent impedance seen by the distance protection relay. Hence, fault classification and fault section identification in a STATCOM connected transmission line by using the traditional impedance based method are a challenge. Since impedance based distance protection relays are widely used for protecting high voltage transmission lines due to their simple operating principle [5], at present, it is essential to design a new distance protection scheme, to ensure reliability considering the impact of FACTS devices.

Many researchers have investigated and addressed the impact analysis of distance protection relays in the presence of shunt FACTS controllers like STATCOM [6]-[9]. But, only a few have presented suggestions to mitigate the impact of FACTS devices for a transmission system protection [10]-[15].

Albasri et al. (2007) highlighted the issues encountered when protecting shunt-FACTS compensated transmission line using distance protection and presented practical solutions to mitigate the adverse effects of shunt-FACTS compensated lines on distance protection schemes [10]. Kazemi et al. (2010) addressed a new adaptive distance protection scheme to mitigate the influence of the STATCOM on the distance relay performance. In this scheme, the tripping characteristic of the adaptive distance relay changes based on the information received from SCADA about STATCOM controlling parameters and the power system conditions [11]. Zhang et al. (2010) analyzed the effect of STATCOM on the performance of distance relay of a transmission line and presented new setting principles. But, the practical difficulty in this concept is that when the system parameter changes, then the setting values have to be adjusted [12]. EI-Zonkoly et al. (2011) proposed a new algorithm to detect and classify the fault and identify the fault position in a transmission line with respect to a midpoint connected FACTS device. Discrete wavelet transformation and wavelet entropy calculations are used to analyze during fault current and voltage signals of the compensated transmission line [13]. Elsamahy et al. (2011) investigated the problem raised by the mid-point connected STATCOM on the coordination between the generator distance phase back up protection and generator capability curves. They concluded from the results that the midpoint STATCOM adversely affected on such coordination. They proposed a new scheme using Support Vector Machine (SVM) to enhance the coordination between such protection and the generator capability curves [14]. Ghazizadeh-Ahsaee et al. (2012) proposed a new fault location algorithm for the transmission lines compensated by the shunt FACTS devices. In this technique, an optimization problem is achieved and then the exact location of fault is determined by solving this optimization problem. Synchronized data from the two ends of the transmission line are utilized for this technique [15]. It is observed from the above authors' literature, that most of the methods and models suffered from complexity and dependency on different calculations, on a large set of founded information.

To overcome the above difficulties, in this paper, a new distance protection scheme using Current Compensation Method (CCM) is proposed to locate the fault correctly by mitigating the problems raised by shunt connected FACTS devices i.e. STATCOM with simple calculations. In this method, the apparent impedance of the distance relay has been corrected based on the STATCOM injected or absorbed current, calculated at the relay location and then the actual distance of the fault point has been calculated. The performance of the proposed fault location method was tested with various types of faults at different locations using MATLAB/SIMULINK software.

\section{Transmission System Model with STATCOM}

The single line diagram of the two-bus test system under analysis is shown in Figure 1, which is the modified version of the test system reported in [12]. The test system consists of a $400 \mathrm{kV} 50 \mathrm{~Hz}, 300 \mathrm{~km}$ length transmission line, with two $6500 \mathrm{MVA}$ equivalent sources $E_{s}$ and $E_{r}$ connected at the sending and receiving end respectively. A 100 MVA STATCOM is installed at the midpoint of the transmission line. The distance relay connected near the sending end (Bus1) is considered for this analysis. 


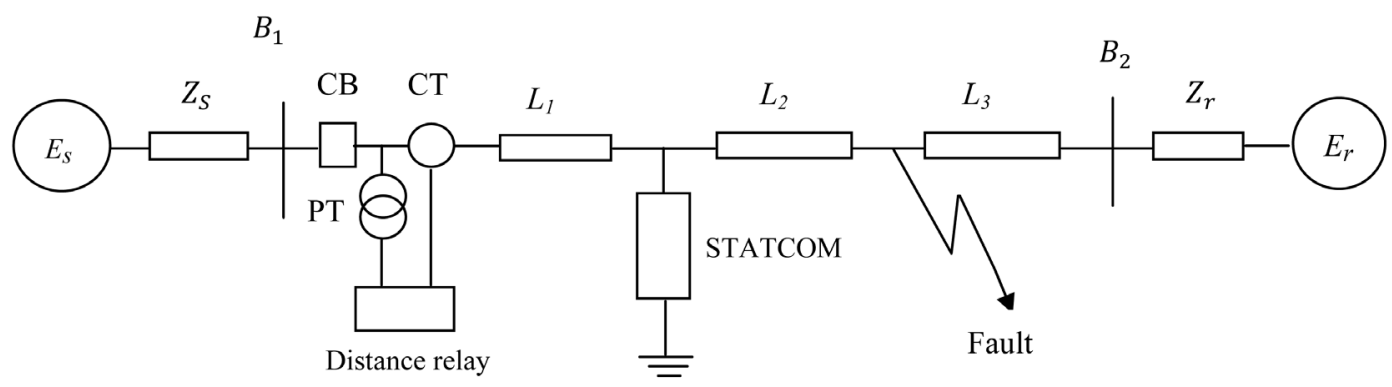

Figure 1. Single line schematic diagram of the test system.

The main function of the midpoint connected STATCOM is to regulate the connecting point voltage of the transmission line to the setting value by supplying or absorbing the reactive current. When a fault occurs in the transmission line, the STATCOM consumes or supplies the reactive power to the transmission line system to regulate the connecting point voltage $\left(\mathrm{V}_{\mathrm{t}}\right)$. The reactive power exchange between STATCOM and the transmission system can be controlled by varying the voltage $\left(V_{s}\right)$ of the three-phase voltage source inverter. If $V_{s}$ is greater than $V_{t}$ STATCOM supplies the reactive power to the system or if $V_{s}$ is less than $V_{t}$ it consumes reactive power from the system. The amplitude of the voltage source inverter can be adjusted by changing the dead angle $\delta$ and/or the DC capacitor voltage [16] [17].

\section{Fault location Estimation Using CCM}

Figure 2 shows the equivalent circuit diagram of the test system for the faults occurring beyond the STATCOM location.

In Figure 2

$E_{R}$ is the voltage measured at the relay point,

$I_{L}$ is the current flowing in the line,

$I_{s h}$ is the current injected by STATCOM,

$I_{R}$ is the current measured at the relay point,

$I_{f}$ is the current flowing in the fault resistance,

$R_{f}$ is the fault resistance,

$Z_{L}$ is the impedance of the transmission line,

$X_{s t}$ is the STATCOM equivalent reactance,

$E_{1} \& E_{2}$ are sending end and receiving end bus voltage,

$I_{1} \quad \& \quad I_{2}$ are sending end and receiving end line current,

$d$ is per unit distance from the relay point to the fault point.

The phase voltage at the relay location can be calculated by using the following equations,

$$
E_{R}=0.5 Z_{L} I_{R}+(d-0.5) Z_{L} I_{s h}+(d-0.5) Z_{L} I_{R}+R_{f} I_{f} .
$$

The apparent impedance seen by the distance relay $\left(Z_{\text {relay }}\right)$ can be estimated by dividing the phase voltage $\left(E_{R}\right)$ with phase current $\left(I_{R}\right)$ at the relay location.

$$
\text { i.e. } Z_{\text {relay }}=0.5 Z_{L}+(d-0.5) Z_{L} \frac{I_{\text {sh }}}{I_{R}}+(d-0.5) Z_{L}+R_{f} \frac{I_{f}}{I_{R}} \text {. }
$$

Assuming the fault to be metallic fault,

$$
Z_{\text {relay }}=d Z_{L}\left(1+\frac{I_{s h}}{I_{R}}\right)-0.5 Z_{L} \frac{I_{s h}}{I_{R}}
$$

The actual apparent impedance is expressed as, 




Figure 2. Equivalent circuit diagram of the test system.

$$
d Z_{L}=\frac{\frac{E_{R}}{I_{R}}+0.5 Z_{L} \frac{I_{s h}}{I_{R}}}{1+\frac{I_{s h}}{I_{R}}}=Z_{A P P} .
$$

It is clear that the actual apparent impedance can be calculated accurately when the STATCOM current $\left(I_{\text {sh }}\right)$ is known [18]. Once the apparent impedance is calculated accurately, then the exact fault location $(d)$ is easily estimated by dividing the actual apparent impedance $\left(Z_{A P P}\right)$ with the line impedance $\left(Z_{L}\right)$.

It is noted that, the phasor variables are chosen based on the type of fault occurring in the power transmission line. For single phase-to-ground fault at phase "A"; these variables are

$$
\begin{gathered}
E_{R}=E_{A} \\
I_{R}=I_{A}+K_{0} I_{0} \\
I_{s h}=I_{s t(A)}-I_{s t(0)} \\
K_{0}=\frac{Z_{0}-Z_{1}}{Z_{1}}
\end{gathered}
$$

where

$E_{A}$ : phase "A" voltage at the relay location,

$I_{A}$ : phase "A" current the relay location,

$I_{0}$ : zero sequence current at the relay location,

$K_{0}$ : zero sequence compensation factor of the line,

$Z_{1}$ : positive sequence impedance of the line,

$Z_{0}$ : zero sequence impedance of the line,

$I_{s t(A)}$ : STATCOM phase "A" current,

$I_{s t(0)}$ : STATCOM zero sequence current.

Similarly, for single phase-to-ground faults in phases "B" and " $\mathrm{C}$ ", the appropriate phase quantities have been used. For line-to-line fault between phase "A" and "B"; these variables are

$$
\begin{gathered}
E_{R}=E_{A}-E_{B} \\
I_{R}=I_{A}-I_{B} \\
I_{s h}=I_{s t(A)}-I_{s t(B)}
\end{gathered}
$$

where

$E_{B}$ : phase "B" voltage at the relay location,

$I_{B}$ : phase "B" current at the relay location, 


\section{$I_{s t(B)}$ : STATCOM phase "B" current.}

Similarly, for line-to-line faults between phases "B" and "C" and phases " $\mathrm{A}$ " and "C", the appropriate phase quantities have to be used.

\section{Proposed Distance Protection Method}

The flowchart of the proposed distance location model is depicted in Figure 3. Instrument transformers are connected to measure the voltage and current signals at the relay point. An analog anti aliasing filter filters the fault transients before sampling, to avoid aliasing of the input waveforms. A data acquisition system with 100 $\mathrm{kHz}$ sampling frequency calculates the signals as a string of samples. The Discrete Fourier Transform (DFT) block, transfers the sampled current and voltage signals to phasor quantities. The STATCOM injected/absorbed current is made available at the relay impedance measurement units with the help of SCADA to calculate the correct value of the apparent impedance. The symmetrical component block produces three symmetrical components from the phase currents. Six impedance measurement equations perform the impedance estimation. Among these, three equations detect faults which involve more than one phase and the remaining three equations detect phase-to-ground faults. Each equation estimates the apparent impedance separately and identifies the fault location. If the apparent impedance estimated by any relay equations is within the characteristic, then a trip signal is issued to the circuit breaker. The relay logic uses the Mho type-operating characteristic.

The equations to estimate the apparent impedance for various fault conditions are listed in Table 1 . For single phase-to-ground fault at phase " $A$ ", the apparent impedance $\left(Z_{A P P}\right)$ is measured by the equations $\left(Z_{A}\right)$. Similarly, for single phase-to-ground faults in phase " $B$ " and " $C$ ", the appropriate measurement equations have been used. For line-to-line fault between phase "A" and "B", the apparent impedance $\left(Z_{A P P}\right)$ measured by the equations $\left(Z_{A B}\right)$.

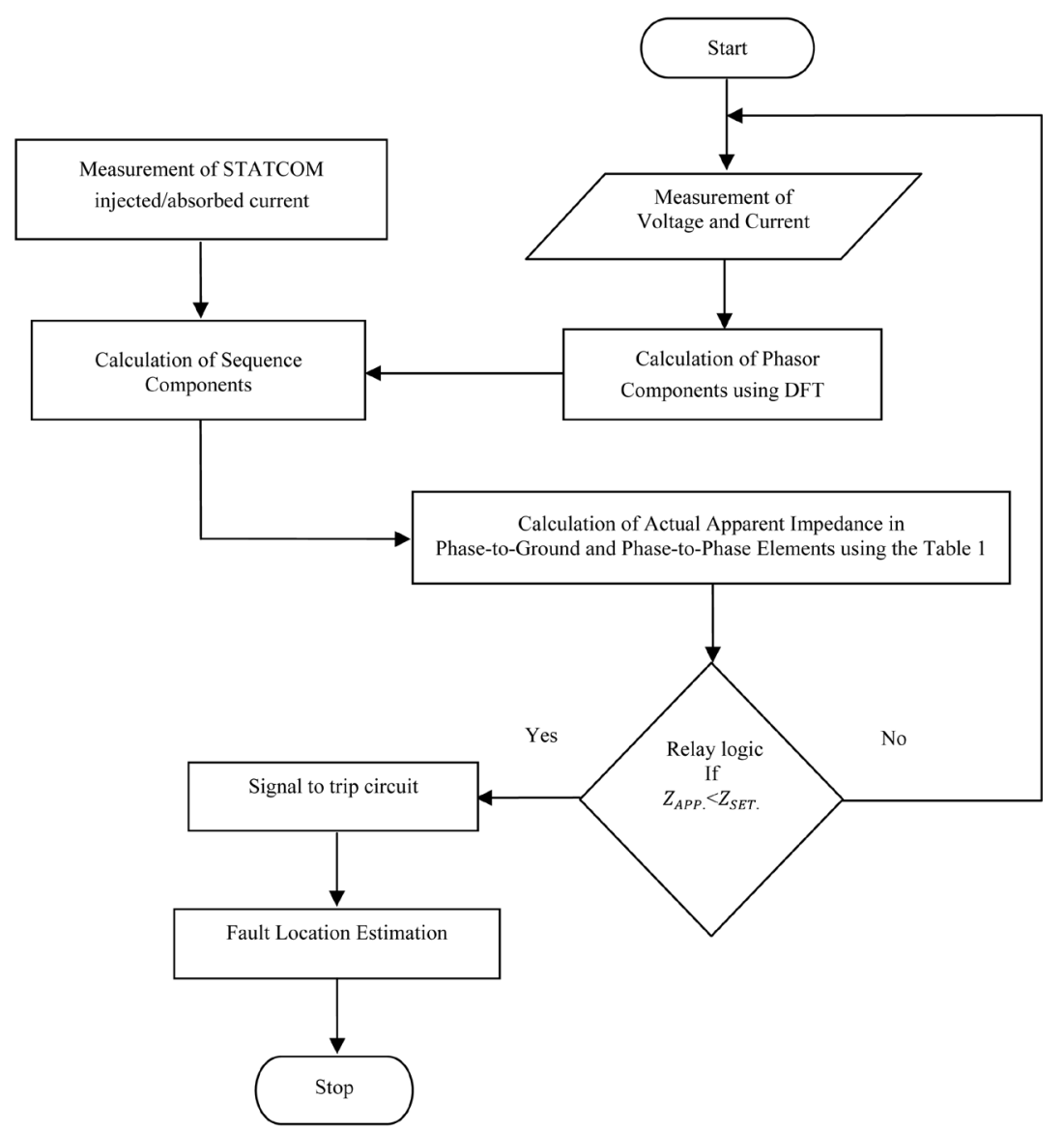

Figure 3. Flowchart of the proposed distance relay model. 
Table 1. Apparent impedance equations for various fault conditions.

Types of fault

"A" phase-ground fault

"B" phase-ground fault

"C" phase-ground fault

“A” phase-“B” phase-fault/“A” phase-"B” phase-ground fault

“B” phase-“C” phase-fault/“B” phase-“C” phase-ground fault

“C” phase-“A” phase-fault/“C” phase-“A” phase-ground fault
Formula for apparent impedance calculation $\left(Z_{\text {APP }}\right)$

$\left(Z_{A}\right)=\frac{\frac{E_{A}}{I_{A}+K_{0} I_{0}}+0.5 Z_{L} \frac{I_{S t(A)}-I_{S t(0)}}{I_{A}+K_{0} I_{0}}}{1+\frac{I_{S t(A)}-I_{S t(0)}}{I_{A}+K_{0} I_{0}}}$

$\left(Z_{B}\right)=\frac{\frac{E_{B}}{I_{B}+K_{0} I_{0}}+0.5 Z_{L} \frac{I_{S t(B)}-I_{S t(0)}}{I_{B}+K_{0} I_{0}}}{1+\frac{I_{S t(B)}-I_{S t(0)}}{I_{B}+K_{0} I_{0}}}$

$\left(Z_{C}\right)=\frac{\frac{E_{C}}{I_{C}+K_{0} I_{0}}+0.5 Z_{L} \frac{I_{S t(C)}-I_{S t(0)}}{I_{C}+K_{0} I_{0}}}{1+\frac{I_{S t(C)}-I_{S t(0)}}{I_{C}+K_{0} I_{0}}}$

$\left(Z_{A B}\right)=\frac{\frac{E_{A}-E_{B}}{I_{A}-I_{B}}+0.5 Z_{L} \frac{I_{S t(A)}-I_{S t(B)}}{I_{A}-I_{B}}}{1+\frac{I_{S t(A)}-I_{S t(B)}}{I_{A}-I_{B}}}$

$\left(Z_{B C}\right)=\frac{\frac{E_{B}-E_{C}}{I_{B}-I_{C}}+0.5 Z_{L} \frac{I_{S t(B)}-I_{S t(C)}}{I_{B}-I_{C}}}{1+\frac{I_{S t(B)}-I_{S t(C)}}{I_{B}-I_{C}}}$

$\left(Z_{C A}\right)=\frac{\frac{E_{C}-E_{A}}{I_{C}-I_{A}}+0.5 Z_{L} \frac{I_{S t(C)}-I_{S t(A)}}{I_{C}-I_{A}}}{1+\frac{I_{S t(C)}-I_{S t(A)}}{I_{C}-I_{A}}}$

Similarly, for line-to-line faults between phases " $B$ ” and “ $C$ ” and phases “ $A$ ” and " $C$ ”, the appropriate equations have to be used. For three phase fault (line-to-line-to-line-ground) any one of the line-to-line fault equations can be used. The STATCOM injected/absorbed current is made available at the relay impedance measurement units to calculate the correct value of the apparent impedance. The SCADA [19], with dedicated communication links provides the information about the STATCOM injected/absorbed current at the relay point.

\section{Simulation Results and Discussion}

Figure 4 shows the MATLAB/ SIMULINK model of the $400 \mathrm{kV} 50 \mathrm{~Hz}, 300 \mathrm{~km}$ length test transmission system with 100 MVA STATCOM to evaluate the performance of the developed fault location algorithm.

The performance of the proposed method, have been evaluated for various types of faults on the transmission system at various locations. The results i.e. three phase voltages and currents obtained at the relay point have been exported as the input to the distance relay model. The Mho relay characteristics at a sampling rate of $6 \mathrm{kHz}$ (120 samples per cycle) have been used to detect the faults. The relay is set to protect $80 \%(240 \mathrm{~km})$ of the transmission line. Even though several cases are involved in the analysis, only two cases of impedance trajectories i.e. "A" phase-to-ground fault and "A" phase-to-" $\mathrm{B}$ ” phase-to-ground fault with zero fault resistance are discussed below. In addition, the effect of the fault occurring before the STATCOM location and after the STATCOM location is also discussed. 


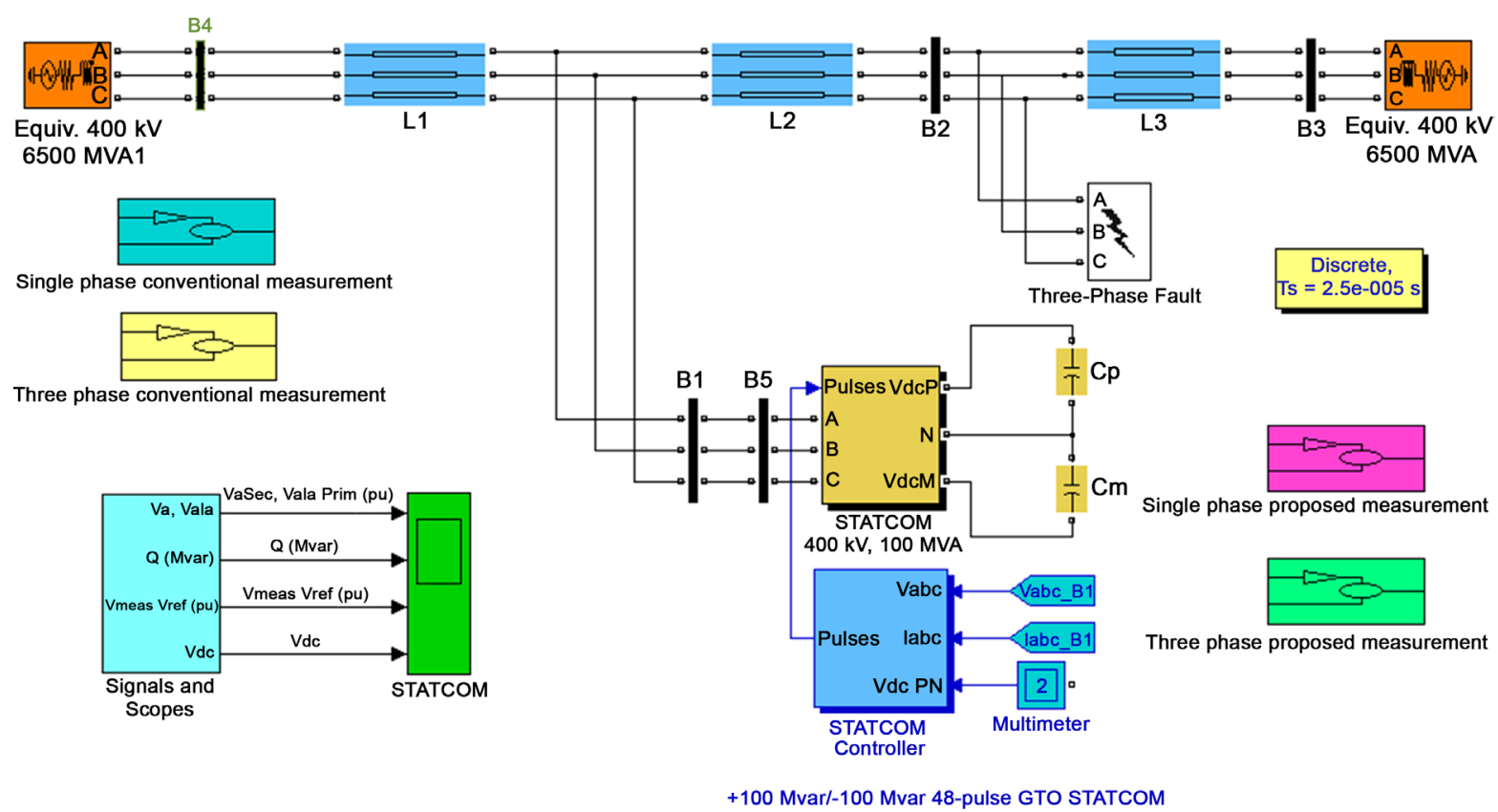

Figure 4. The Simulink model used to simulate the proposed algorithm.

\subsection{Impedance Trajectories for Single Phase Fault}

Apparent impedance trajectories of the conventional distance relay and the proposed distance relay with Mho characteristic for "A" phase-to-ground fault occurring at the fault distance of $240 \mathrm{~km}$ is shown in Figure 5. It is evident that the apparent impedance seen in the conventional distance is higher (80.98 ohms) than that of the apparent impedance seen by the proposed distance relay (77.05 ohms), which is outside the Mho characteristic, as during the fault, the reactive power injected by the STATCOM increases the voltage at the connecting point which, in turn increases the apparent impedance seen by the conventional distance relay.

Therefore, the conventional distance relay under reaches and hence it does not give the trip signal. But the apparent impedance seen by the proposed distance relay is almost same as the impedance seen by the conventional distance relay without STATCOM which settles inside the Mho characteristic and issues the trip signal correctly.

The test results of the transmission system the conventional distance relay and the proposed distance relay for "A" phase to ground fault are shown in Table 2. It clearly shows that when the fault occurs between the relay point and the STATCOM location (between 10 and 150 kilometers, in this case), there is not much change in the apparent impedance measured by the distance relay i.e. measured impedance is almost the same as that of the system without STATCOM.

For example, when the fault occurs at $120 \mathrm{~km}$, the apparent impedance measured by the conventional distance relay is 38.58 ohms and the proposed distance relay is 38.57 ohms. This is due to the fact that when the STATCOM is not present in the fault loop, then the measured impedance is equal to actual line impedance of the line section between the relay point and the fault point.

When the fault ("A" phase-to-ground fault) occurs beyond the STATCOM location i.e. between 150 and 300 kilometers, the apparent impedance of the system is greater as the STATCOM is involved in the fault loop. It is observed that (refer to Table 2) when the fault occurs at a distance of $240 \mathrm{~km}$, the proposed distance relay measures 77.05 ohms, whereas the conventional distance relay measures the apparent impedance as 80.98 ohms, which is higher than that of the proposed distance relay measurement.

\subsection{Impedance Trajectories of Phase-to-Phase Fault}

The impedance trajectory of the conventional distance relay and proposed distance relay for "A" phase-to-"B" phase-to-ground fault created at a distance of $240 \mathrm{~km}$ is shown in Figure 6. It clearly shows that the protection 


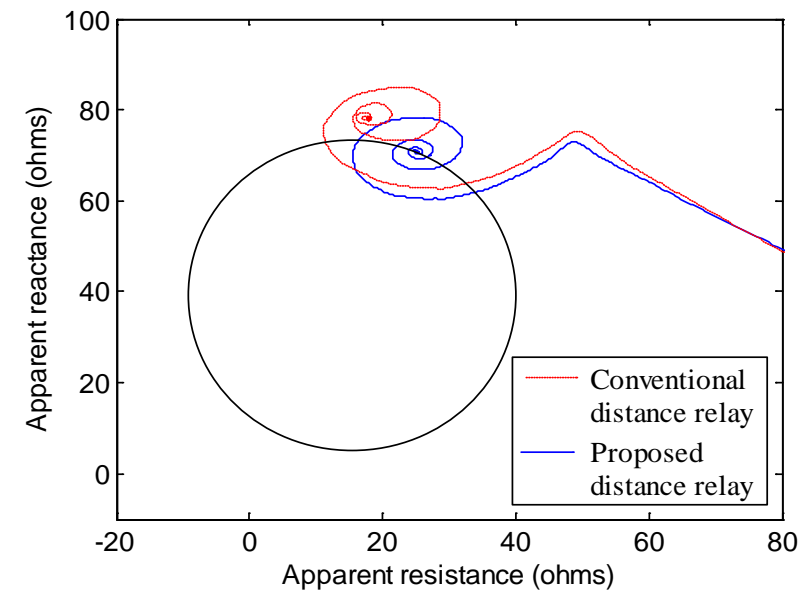

Figure 5. The apparent impedance trajectories for single phase fault.

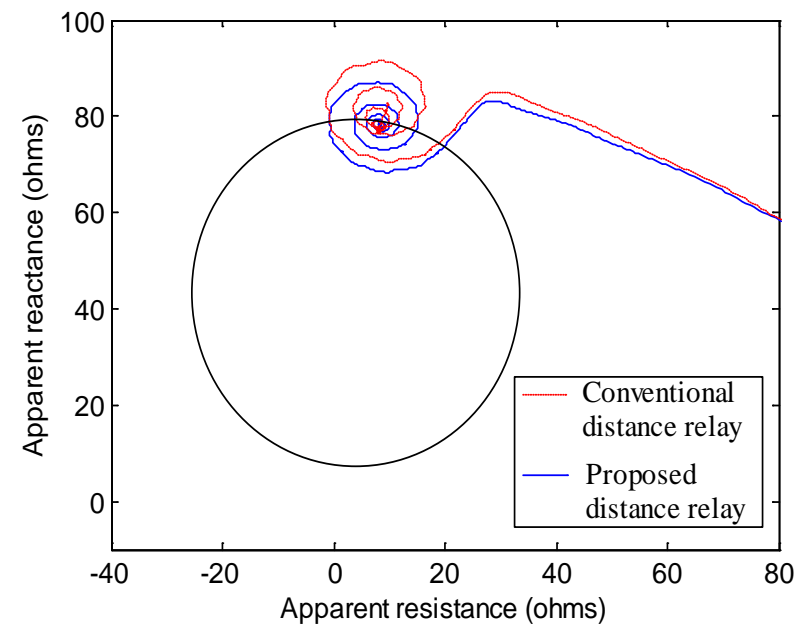

Figure 6. The apparent impedance trajectories for phase-to-phase fault.

Table 2. Variations of the apparent impedance for "A" phase-to-ground fault.

\begin{tabular}{ccc}
\hline \multirow{2}{*}{ Fault location in km } & \multicolumn{2}{c}{ Apparent impedance in ohms with STATCOM } \\
\cline { 2 - 3 } 20 & 06.37 & Using proposed distance relay \\
40 & 12.89 & 06.35 \\
60 & 19.25 & 12.89 \\
80 & 25.88 & 19.25 \\
100 & 32.00 & 25.88 \\
120 & 38.58 & 32.10 \\
140 & 44.98 & 38.57 \\
160 & 51.98 & 44.99 \\
180 & 59.25 & 50.98 \\
200 & 68.11 & 57.60 \\
220 & 74.38 & 63.90 \\
240 & 80.98 & 70.62 \\
260 & 88.94 & 77.05 \\
280 & 97.88 & 83.21 \\
& & 89.65 \\
\hline
\end{tabular}


zone of the conventional distance relay under reaches, whereas the proposed distance relay estimates the exact, apparent impedance of the transmission system and operates as anticipated.

The variations of the apparent impedance for "A" phase-to-"B" phase-to-ground fault with different fault locations of the conventional distance relay and the proposed distance relay are shown in Table 3. For a system with STATCOM, it is observed that when the fault occurs before the STATCOM location, the proposed distance relay and conventional distance relay measure almost the same values. But, if the fault occurs after SATACOM location i.e. for $240 \mathrm{~km}$, the proposed distance relay measures $77.03 \mathrm{ohms}$ and conventional distance relay measures 78.58 ohms. It clearly shows that when the fault occurs between the relay location and after the STATCOM location, the conventional distance relay measurement is higher than that of the proposed distance relay measurement.

The results (refer to Table 3) show that the new proposed distance protection method effectively mitigates the impact of STATCOM on the apparent impedance measurement of the distance relay and functions properly without error.

\subsection{Estimation of Fault Location}

The test results under several fault scenarios with different fault locations are shown in Table 4. The table consists of fault type, fault location, estimated fault location using conventional measurements and the proposed distance relay measurements. A single-phase fault ("A" phase-to-ground fault) condition is an example, where when the fault is at $240 \mathrm{~km}$, the estimated fault location based on conventional measurement is $253 \mathrm{~km}$, but estimated fault location based on the proposed distance relay measurement is $240.7 \mathrm{~km}$.

Similarly, for the phase-to-phase fault ("A" phase-to-"B” phase-to-ground fault) condition, the estimated fault location based on conventional distance relay measurement is $245.5 \mathrm{~km}$, but the estimated fault location based on the proposed distance relay measurement is $240.7 \mathrm{~km}$. In almost all the cases the proposed distance relay measurement error is below $0.3 \%$. The results clearly show that the proposed distance protection method to estimates the fault location correctly and effectively mitigates the impact of STATCOM on the distance relay performance for various fault conditions.

Table 3. Variations of the apparent impedance for "A" phase-to-"B" phase-to-ground fault.

\begin{tabular}{|c|c|c|}
\hline \multirow{2}{*}{ Fault location in km } & \multicolumn{2}{|c|}{ Apparent impedance in ohms with STATCOM } \\
\hline & Using conventional distance relay & Using proposed distance relay \\
\hline 20 & 06.37 & 06.37 \\
\hline 40 & 12.73 & 12.73 \\
\hline 60 & 19.08 & 19.08 \\
\hline 80 & 25.42 & 25.42 \\
\hline 100 & 31.70 & 31.75 \\
\hline 120 & 38.58 & 38.09 \\
\hline 140 & 45.20 & 44.88 \\
\hline 160 & 51.70 & 50.87 \\
\hline 180 & 58.91 & 57.66 \\
\hline 200 & 65.04 & 63.88 \\
\hline 220 & 71.69 & 70.62 \\
\hline 240 & 78.58 & 77.03 \\
\hline 260 & 85.57 & 83.40 \\
\hline 280 & 92.64 & 89.68 \\
\hline
\end{tabular}


Table 4. Estimation of fault location with types of faults.

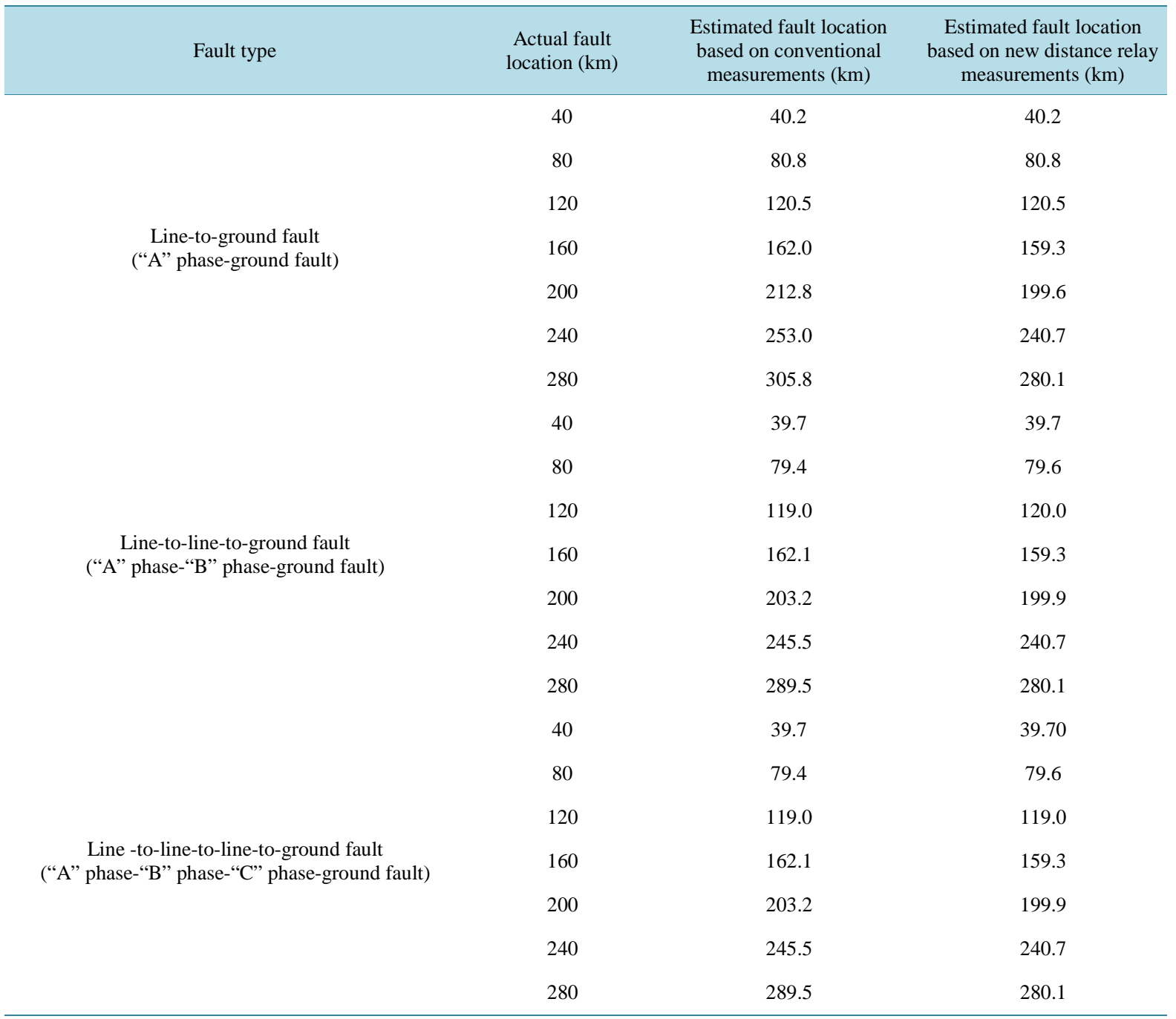

\section{Conclusion}

A fault location method for STATCOM connected transmission line distance protection using Current Compensation Method (CCM) was developed and tested successfully to overcome the problems arising from the conventional methods. The fault loop apparent impedance in the proposed method is corrected based on the STATCOM injected/absorbed current and accordingly the actual distance to the fault is calculated. Comprehensive equations required for new digital distance relay to calculate the accurate fault location are derived. Test results proved that the proposed method yielded accurate estimates of the fault location and effectively mitigated the impact of STATCOM on the distance relay performance. The accuracy of the proposed method is high in almost all the cases and the error is kept below $0.3 \%$. By using the proposed method, it is possible to design an accurate and reliable distance protection scheme for STATCOM compensated transmission lines.

\section{References}

[1] Hingorani, N.G. and Gyugyi, L. (2000) Understanding FACTS: Concepts and Technology of Flexible AC Transmission Systems. IEEE Press, New York.

[2] Padiyar, K.R. (2007) Facts Controllers in Power Transmission and Distribution. New Age International Publishers, New Delhi.

[3] Abido, M.A. (2009) Power System Stability Enhancement Using FACTS Controllers: A Review. The Ara bian Journal 
for Science and Engineering, 34, 153-172.

[4] El-Moursi, M.S. and Sharaf, A.M. (2005) Novel Controllers for the 48-Pulse VSC STATCOM and SSSC for Voltage Regulation and Reactive Power Compensation. IEEE Transactions on Power Systems, 20, 1985-1987. http://dx.doi.org/10.1109/TPWRS.2005.856996

[5] Ziegler, G. (2011) Numerical Distance Protection Principles and Applications. John Wiley \& Sons, Germany.

[6] El-Arroudi, K., Joos, G. and McGillis, D.T. (2002) Operation of Impedance Protection Relays with the STATCOM. IEEE Transactions on Power Delivery, 17, 381-387. http://dx.doi.org/10.1109/61.997904

[7] Zhou, X.Y., Wang, H.F., Aggarwal, R.K. and Beaumont, P. (2005) The Impact of STATCOM on Distance Relay. 15th PSCC, Liege, 22-26 August 2005, 1-7.

[8] Sidhu, T.S., Varma, R.K., Gangadharan, P.K., Albasri, F.A. and Ortiz, G.R. (2005) Performance of Distance Relays on Shunt-FACTS Compensated Transmission Lines. IEEE Transactions on Power Delivery, 20, 1837-1845. http://dx.doi.org/10.1109/TPWRD.2005.848641

[9] Albasri, F.A., Sidhu, T.S. and Varma, R.K. (2007) Performance Comparison of Distance Protection Schemes for Shunt-FACTS Compensated Transmission Lines. IEEE Transactions on Power Delivery, 22, 2116-2125. http://dx.doi.org/10.1109/TPWRD.2007.900283

[10] Albasri, F.A., Sidhu, T.S., Varma, R.K. and Rajiv, K. (2007) Mitigation of Adverse Effects of Midpoint ShuntFACTS Compensated Transmission Lines on Distance Protection Schemes. Proceedings of the IEEE/PES General Meeting 2007, Tampa, FL, 24-28 June 2007, 1-8. http://dx.doi.org/10.1109/pes.2007.386230

[11] Kazemi, A., Jamali, S. and Shateri, H. (2010) Adaptive Distance Protection in Presence of STATCOM on a Transmission Line. Proceedings of the Transmission and Distribution Conference and Exposition IEEE/PES, New Orleans, LA, USA, 19-22 April 2010, 1-6. http://dx.doi.org/10.1109/tdc.2010.5484350

[12] Zhang, W.H., Lee, S.J. and Choi, M.S. (2010) Setting Considerations of Distance Relay for Transmission Line with STATCOM. Journal of Electrical Engineering \& Technology, 5, 522-529. http://dx.doi.org/10.5370/JEET.2010.5.4.522

[13] EI-Zonkoly, A.M. and Desouki, H. (2011) Wavelet Entropy Based Algorithm for Fault Detection and Classification in FACTS Compensated Transmission Line. Journal of Energy and Power Engineering, 3, 34-42. http://dx.doi.org/10.4236/epe.2011.31006

[14] Elsamahy, M., Sidhu, T.S. and Ramakrishna, G. (2011) Enhancement of the Coordination Between Generator Phase Backup Protection and Generator Capability Curves in the Presence of a Midpoint STATCOM Using Support Vector Machines. IEEE Transaction on Power Delivery, 26, 1841-1853. http://dx.doi.org/10.1109/TPWRD.2011.2123922

[15] Ghazizadeh-Ahsaee, M. and Sadeh, J. (2012) Accurate Fault Location Algorithm for Transmission Lines in the Presence of Shunt-Connected Flexible AC Transmission System Devices. Journal of IET Generation Transmission \& Distribution, 6, 247-255. http://dx.doi.org/10.1049/iet-gtd.2011.0657

[16] Natick, M.A. (2007) Sim Power Systems 4-Reference Manual. The Math Works, Inc.

[17] Sybille, G. and Le-Huy, H. (2000) Digital Simulation of Power Systems and Power Electronics Using the MATLAB/ Simulink Power System Block Set. Proceedings of the IEEE Power Engineering Society Winter Meeting, Singapore, 23-27 January 2000, 2973-2981. http://dx.doi.org/10.1109/PESW.2000.847358

[18] Ilango, R. and Sree Renga Raja, T. (2014) Accurate Distance Protection Scheme for Transmission Line Fault Location Considering the Impact of Shunt Connected STATCOM Middle-East Journal of Scientific Research, 21, 2123-2129.

[19] Kusic, G.L. and Garrison, D.L. (2004) Measurement of Transmission Line Parameters from SCADA Data. Proceedings of the IEEE/PES, Power Systems Conference and Exposition, New York, NY, 10-13 October 2004, 440-445. http://dx.doi.org/10.1109/psce.2004.1397479 


\section{Submit or recommend next manuscript to SCIRP and we will provide best service for you:}

Accepting pre-submission inquiries through Email, Facebook, LinkedIn, Twitter, etc.

A wide selection of journals (inclusive of 9 subjects, more than 200 journals)

Providing 24-hour high-quality service

User-friendly online submission system

Fair and swift peer-review system

Efficient typesetting and proofreading procedure

Display of the result of downloads and visits, as well as the number of cited articles

Maximum dissemination of your research work

Submit your manuscript at: http://papersubmission.scirp.org/ 